\title{
Pinching, electrocution, ravens' beaks, and positive pressure ventilation: a brief history of neonatal resuscitation
}

\author{
C P F O'Donnell, A T Gibson, P G Davis
}

Arch Dis Child Fetal Neonatal Ed 2006;91:F369-F373. doi: 10.1136/adc.2005.089029

Since ancient times many different methods have been used to revive newborns. Although subject to the vagaries of fashion for 2000 years, artificial respiration has been accepted as the mainstay of neonatal resuscitation for about the last 40 . Formal teaching programmes have evolved over the last 20 years. The last 10 years have seen international collaboration, which has resulted in careful evaluation of the available evidence and publication of recommendations for clinical practice. There is, however, little evidence to support current recommendations, which are largely based on expert opinion. The challenge for neonatologists today is to gather robust evidence to support or refute these recommendations, thereby refining this common and important intervention.

See end of article for authors' affiliations

Correspondence to: Dr O'Donnell, Royal Women's Hospital Melbourne 132 Grattan

Street, Carlton, Victoria 3053, Australia;

codonnell@nmh.ie

Accepted 17 January 2006
"And when Elisha was come into the house, behold, the child was dead, and laid upon his bed... He went up, and lay upon the child, and put his mouth upon his mouth ... and the flesh of the child waxed warm... and the child opened his eyes."

Old Testament'

"One may give a woman (about to give birth) all assistance possible... one may violate the Sabbath on her account ... What is meant by "being of assistance"? ... holding up the young, blowing air into its nostrils, and leading it to its mother's breast, so that it may suck." Babylonian Talmud ${ }^{2}$

"On the subject of resuscitation, knowledge and practice have now reached a very satisfactory level of completeness."

Yandell Henderson $1928^{3}$

"Since intubation and positive pressure ventilation were first recommended... a pattern of resuscitation has evolved based on extrapolation and assumption rather than clinical measurement. There can be few areas of medicine where the potential benefit is so great but which have been subjected to so little evaluation"

AD Milner $1991^{4}$

\section{ANCIENT HISTORY}

Death of newborns from respiratory failure was recognised in ancient times. Chinese emperor and philosopher Hwang-Ti (2698-2599 BC) noted that this occurred more commonly among infants born prematurely. ${ }^{5}$ Increased mortality among premature infants was also reported in Eber's Papyrus in Egypt (1552 BC), and accounts of resuscitation are found in the old Testament. ${ }^{1}$ Descriptions of artificial breathing for newborn humans ${ }^{2}$ and reviving a newborn lamb by inserting a reed through the trachea are contained in the Talmud (200BC-400AD), ${ }^{6}$ and Hippocrates (460-380BC) described intubation of the trachea of humans to support ventilation. ${ }^{5}$ Soranus of Ephesus (98-138AD) described "how to recognise the newborn that is worth rearing"7 and criticised "the majority of barbarians" for the practice of immersion of the newborn baby in cold water.

Air movement and the means by which it was achieved were often perceived as curiosities and were "discovered" on many occasions. Galen (129-199AD) inflated the lungs of dead animals via the trachea with a bellows and concluded that air movement caused chest "arises". ${ }^{5}$ The significance of his finding was not appreciated, however, as further work on ventilation did not occur for centuries. ${ }^{8}$ Muslim philosopher and physician Avicenna (980-1037AD) described intubation of the trachea using "a cannula of gold or silver" around 1000 AD. ${ }^{9}$ Rabbi Maimonides (1135-1204) described how to detect respiratory arrest in newborns and a method of manual resuscitation. ${ }^{5}$ In 1472 Paulus Bagellardus published the first book on childhood diseases and described mouth to mouth resuscitation of the newborn. ${ }^{5}$ Paracelsus (1493-1541) used a bellows inserted into the nostrils of drowned humans in an attempt to inflate their lungs. ${ }^{6}$ In 1543, Belgian anatomist Andreas Vesalius (1514-1564) performed a tracheostomy, intubation, and ventilation on a pregnant sow. ${ }^{8}$ In 1667 English scientist Robert Hook kept a dog alive for over an hour, ventilating it with a fireside bellows attached directly to the trachea. ${ }^{8}$

\section{$1700-1850$}

Before the mid-1700s, divine intervention was credited for most cases of successful resuscitation. However, a presentation to the Royal Society of London by surgeon William Tossach in 1745 aroused interest. ${ }^{8}$ He reported the successful revival of James Blair, a coal miner overcome by smoke, using mouth to mouth resuscitation (a technique apparently used at that time by midwives to revive stillborn infants). ${ }^{6}$ The Royal Society were not impressed however, maintaining that "life ends when 
breathing ceases". Swiss naturalist Antoine Réamur (16831757) presented further reports of successful mouth to mouth resuscitation in Paris. ${ }^{8}$ Growing interest led to the foundation of resuscitation societies in Europe in the late 18th century. Founded in London in 1774, The Institution for Affording Immediate Relief to Persons Apparently Dead from Drowning (soon to become The Society for People Apparently Drowned and, in 1787, The Royal Humane Society) formalised resuscitation education and awarded certificates for excellence. ${ }^{6}$ It served as a template for societies subsequently founded in America, which in turn preceded organisations such as the American Red Cross and American Heart Association. ${ }^{8}$ Although the original guidelines for resuscitation contained such valuable suggestions as warmth and mouth to mouth ventilation, they also advocated rectal fumigation with tobacco smoke, preferably with a bellows, but failing that with a common clay pipe.

Hippocrates (460-377BC) had previously proposed a life giving constituent of air, and Robert Boyle (1627-1691) had demonstrated that larks, sparrows, and mice died if placed in vacuum chambers. Joseph Priestly (1733-1804), an English chemist, however, first isolated "dephlogisticated air" in $1774 .{ }^{5{ }^{8}} \mathrm{He}$ noted that it kept mice alive and caused candle flames to burn brighter. Antoine-Laurent Lavoisier (17431794) termed the gas "the acid producer" or "oxygine". ${ }^{6}$ With Pierre-Simon de Laplace (1749-1827), he showed that respiration was an oxidative process in which water and carbon dioxide were formed as byproducts ${ }^{8}$ and showed that the lungs take in oxygen and excrete carbon dioxide. There are accounts of Chaussier (see below) giving oxygen to newborns in $1780 .^{5}$

In 1752 Scottish obstetrician, William Smellie, outlined the standard approach to apparently lifeless newborns which included " ... the head, temples and breast rubbed with spirits; garlic, onion or mustard applied to the mouth and nose $\mathrm{e}^{\prime \prime}{ }^{10}$ He advocated a form of artificial respiration and described a straight endotracheal tube for resuscitating newborns, while, in 1754, Benjamin Pugh related his experiences of resuscitating infants using mouth to mouth and an endotracheal tube. ${ }^{5}$ Between 1774 and 1776, the Royal Humane Society in London advocated mouth to mouth resuscitation of stillborn infants. Influential Scottish obstetrician, William Hunter (1781-1783), however, denounced it as "the method practiced by the vulgar to restore stillborn children". ${ }^{6}$ Hunter subsequently designed a bellows for inflating the lungs, and, by 1782, the Royal Humane Society recommended the use of bellows rather than mouth to mouth. ${ }^{8}$ This method remained popular for the next 50 years, although mouth to mouth and mouth to endotracheal tube were still advocated by both François Chaussier (17461828), Professor of Obstetrics at the Academy of Science in Paris, and James Blundell (1790-1878), obstetrician at Guy's Hospital, London. ${ }^{5}$ In 1827 Leroy d'Etiolles described the association between ventilation and pneumothoraces in a lecture in Paris. ${ }^{5}$ Subsequently, both mouth to mouth and bellows inflation fell out of favour and remained so for more than a hundred years.

\section{$1850-1950$}

Techniques advocated and used to resuscitate newborns during this period included: swinging the infant upside down (the Schultze method; fig 1$)^{5611}$; squeezing the chest (Prochownich method, among others); raising and lowering the arms while an assistant compressed the chest (the Sylvester method) ${ }^{6}$; rhythmic traction of the tongue (the Laborde method) ${ }^{6}$; tickling the chest, mouth, or throat; yelling; shaking ${ }^{6}$; dilating the rectum using a raven's beak ${ }^{12}$ or a corn cob (a technique allegedly also used by anaesthetists to help initiate breathing on recovery from anaesthesia); immersion in cold water, sometimes alternating with immersion in hot water ; rubbing, slapping, and pinching ${ }^{6}$; electric shocks ${ }^{6}$; nebulisation of brandy mist; insufflation of tobacco smoke into the rectum. ${ }^{5}$

Interest in respiratory support also continued. In 1879, Gairal, a French obstetrician, described the "aerophore pulmonaire" (a rubber bulb connected to a J-shaped tube placed in the infants' upper airway) for positive pressure ventilation. ${ }^{5}$ In 1887, use of the Fell-O'Dwyer device, a foot operated bellows attached to a bulb like implement, for longer term ventilation in a large series of infants was reported. ${ }^{5}$ Alexander Graham Bell described a negative pressure ventilator in $1889 .{ }^{6}$ In 1914, Von Reuss described the use of continuous positive airways pressure for resuscitation of newborn infants. ${ }^{5}$ In the United States in 1928, Henderson advocated positive pressure ventilation with a Tpiece via a mask, ${ }^{3}$ and Flagg recommended endotracheal intubation for positive pressure ventilation using described equipment similar to that in use today. ${ }^{13}$ Blaikely and Gibberd $^{5}{ }^{14}$ subsequently recommended endotracheal intubation and positive pressure ventilation in the United Kingdom in 1935. In 1949, Julius Hess and Evelyn Lundeen published their textbook The premature infant: medical and nursery care. ${ }^{5}$ They stressed the importance of delaying premature delivery, avoiding opiates, scopolamine, and barbiturates before delivery, minimising the use of general anaesthesia, minimal and gentle handling of the infant, clearing the air passages before resuscitation, and administering oxygen.

\section{0-1999}

Insufflation of oxygen into the stomachs of asphyxiated newborns was recommended in the 1950s. ${ }^{15}$ However, the popularity this technique enjoyed during this decade waned over the following one, after evaluation suggested it was ineffective. ${ }^{16}$

Observing that more infants required resuscitation after caesarean section than vaginal delivery, Allan P Bloxsom (1901-1991) introduced his positive pressure air lock in 1950. Infants placed in this metal device were subjected to $60 \%$ oxygen and cyclical increases in pressure of 1-3 psi at one minute intervals to simulate uterine contractions during labour. Bloxsom reported that only 11 of the 55 infants "processed in the lock in an attempt to habituate them to extrauterine conditions" had died, ${ }^{17}$ and editorials in leading journals strongly advocated the use of the chamber. In 1956, a randomised trial comparing the Bloxsom air lock with standard care in an incubator was reported..$^{18}$ No difference in mortality or relief of respiratory distress was found, and use of the air lock declined. Pressure chambers were used for neonatal resuscitation in the United Kingdom during the 1960s; of note, a trial comparing their use with endotracheal ventilation found them equally effective. ${ }^{19}$

Advances in artificial respiration for adults occurred at this time. In 1949 and 1950, Archer Gordon evaluated the most popular methods of respiratory support (arm lift and chest pressure) and concluded they were of marginal benefit. Between 1954 and 1957, James Elam and Peter Safar performed experiments in Baltimore on volunteers from their medical and nursing colleagues.9 ${ }^{20}$ Sedating and paralysing subjects, they demonstrated that airway opening manoeuvres (head tilt, chin lift) and mouth to mouth resuscitation were effective. Dwindling compressed gas supplies caused by a Danish lorry drivers' strike prompted Henning Ruben to invent a self inflating resuscitation bag in 1954. His original device consisted of bicycle spokes welded together and fitted inside an anaesthesia bag. He later modified and described it in 1957..21

Virginia Apgar (1909-1974), an obstetric anaesthesiologist at Columbia, New York, presented a method of assessing 


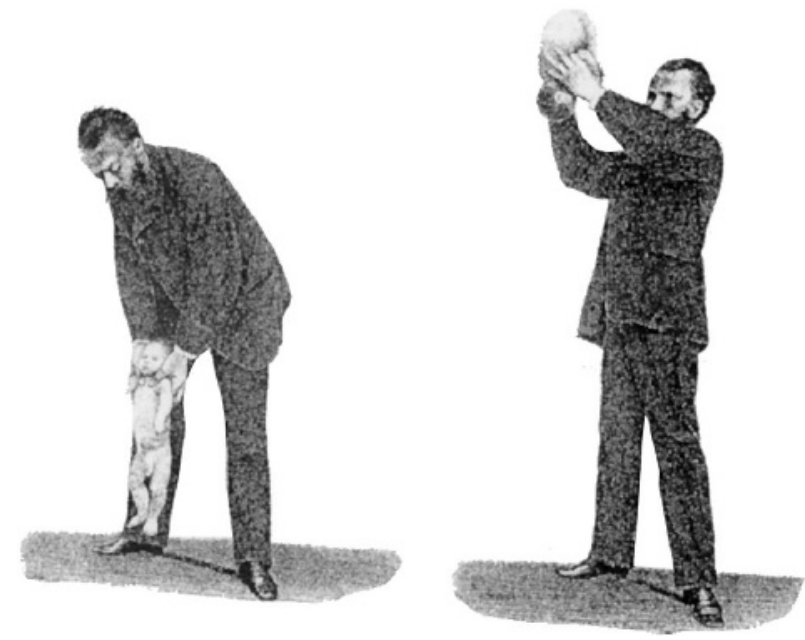

Figure 1 Illustration (reputedly of Dr Bernhard Schultze himself) demonstrating the Schultze method of neonatal resuscitation. From Schultze BS. Der Scheintod Neugeborener. Jenna: Mauke's Verlag, 1871.

newborns in 1952 and published it the following year. ${ }^{22}$ Its purpose was "the re-establishment of simple, clear classification or 'grading' of newborn infants which can be used as a basis for discussion and comparison of the results of obstetric practices, types of maternal pain relief and the effects of resuscitation". Her score prompted new focus on the newborn infant in the delivery room and is still assigned almost universally today. In 1963 Herbert Barrie again described equipment similar to that in use today and recommended guidelines for resuscitation. These included the oral administration of Vandid (vanillic acid $N, N$-diethylamide, a strychnine derivative) if apnoea persisted for more than three minutes.

The 1960s and 1970s saw a flood of new technology and methods of care for acutely ill adults and children. In the United States in 1966, the National Academy of Sciences recommended standardised guidelines for adult resuscitation. In the 1970s, the American Heart Association (AHA) and American Academy of Pediatrics (AAP) recognised the need to improve the care of the compromised newborn. ${ }^{8}$ The National Institute of Health funded projects to provide education on neonatal care to community hospitals. Ron Bloom and Catherine Cropley from Los Angeles developed the curriculum for these programmes, which they called the Neonatal Education Program (NEP). ${ }^{8}$ In 1985 a joint AHA/ AAP committee was convened, which developed the Neonatal Resuscitation Program (NRP) based on the NEP. Published in 1987, the first NRP textbook was based on a consensus of US opinion leaders in neonatology as to what was "accepted" practice. ${ }^{58}$ To date, this programme has been taught to over 1.4 million healthcare providers in the United States alone. ${ }^{23}$ In the United Kingdom in 1980, Edmund Hey wrote a booklet to help midwives, nurses, and doctors caring for newly born infants. ${ }^{24}$ This booklet complemented a course in neonatal resuscitation taught in the Northern Health Region of the United Kingdom. Further editions were subsequently published by the Northern Neonatal Network, and formed the basis for the Newborn Life Support Course

Table 1 Randomised and quasi-randomised trials (identified by lead author and year of publication) evaluating neonatal resuscitation interventions

\begin{tabular}{|c|c|c|}
\hline Study & Interventions compared & $\mathbf{n}$ \\
\hline Reichelderfer $1956^{18}$ & Bloxsom Air Lock versus Isolette incubator & 143 \\
\hline Hutchinson $1966^{19}$ & Hyperbaric oxygen chamber versus intubation and PPV & 218 \\
\hline Drew $1982^{35}$ & Routine versus "selective" intubation for premature infants & 165 \\
\hline Davies $1985^{36}$ & Laerdal versus Samson self inflating bag for PPV & 20 \\
\hline Ramii 1993 ${ }^{37}$ & Air versus $100 \%$ oxygen for PPV & 84 \\
\hline Saugstad $1998^{38}$ & Air versus $100 \%$ oxygen for PPV & 609 \\
\hline Vohra $1999^{32}$ & Polyethylene wrapping versus drying and wrapping with towels for premature infants & 62 \\
\hline Wiswell $2000^{30}$ & $\begin{array}{l}\text { Endotracheal intubation and suction versus expectant management for vigorous } \\
\text { infants born through meconium stained liquor }\end{array}$ & 2094 \\
\hline Vento $2001^{39}$ & Air versus $100 \%$ oxygen for PPV & 40 \\
\hline Ramji $2003^{40}$ & Air versus $100 \%$ oxygen for PPV & 431 \\
\hline Vento $2003^{41}$ & Air versus $100 \%$ oxygen for PPV & 106 \\
\hline Vain $2004^{31}$ & $\begin{array}{l}\text { Intrapartum oropharyngeal and nasopharyngeal suction of infants born through } \\
\text { meconium stained liquor }\end{array}$ & 2514 \\
\hline Vohra $2004^{33}$ & Polyethylene wrapping versus drying and wrapping with towels for premature infants & 55 \\
\hline Lokesh $2004^{42}$ & Sodium bicarbonate infusion versus $5 \%$ dextrose infusion & 55 \\
\hline Finer $2004^{43}$ & PEEP/CPAP versus no CPAP/PEEP for extremely preterm infants & 104 \\
\hline Bajai $2005^{44}$ & Air versus $100 \%$ oxygen for PPV & 204 \\
\hline Harling $2005^{45}$ & PPV with $50 \%$ oxygen versus PPV with $100 \%$ oxygen for preterm infants & 52 \\
\hline Harling $2005^{46}$ & $\begin{array}{l}\text { Sustained ( } 5 \text { second) positive pressure inflation versus } 2 \text { second inflations for preterm } \\
\text { infants }\end{array}$ & 52 \\
\hline Lindner $2005^{47}$ & $\begin{array}{l}\text { Sustained ( } 15 \text { second) positive pressure inflation versus } 1 \text { second inflations for preterm } \\
\text { infants }\end{array}$ & 61 \\
\hline
\end{tabular}

$n$, number of participants reported in the study; PPV, positive pressure ventilation; PEEP, positive end expiratory pressure; CPAP, continuous positive airways pressure. 
developed by the Resuscitation Council UK and published in $2001 .^{24}$

The International Liaison Committee on Resuscitation (ILCOR) was formed in 1992 to provide a forum for liaison between resuscitation organisations in the developed world ${ }^{25}$ and led to publication of consensus international advisory statements on resuscitation in $1997 .{ }^{26}$ The advisory statement on paediatric resuscitation made recommendations for basic and advanced paediatric life support and for basic life support for the newly born..$^{27}$ It noted that "the paucity of pediatric and newborn clinical resuscitation outcome data makes scientific justification of recommendations difficult" ${ }^{\prime 2}{ }^{27}$ Discussion of advanced life support for newborns was considered beyond the scope of the document. Subsequently, the NRP Steering Committee, the New Zealand Resuscitation Council, and the World Health Organisation joined the ILCOR Pediatric Working Group to make recommendations for advanced life support for newborns. Review of the guidelines of the constituent organisations and international literature formed the basis for these recommendations

\section{9-2005}

IN 1999 ILCOR published an advisory statement summarising international consensus on resuscitation of the newly born infant at the time. ${ }^{25}$ The Neonatal Subcommittee of ILCOR reconvenes approximately every five years to evaluate available evidence that may support a change in the recommendations. This large concerted effort has resulted in the publication of updated guidelines in $2000^{28}$ and December 2005. ${ }^{29}$ The recommendations on the management of infants born through meconium stained liquor, oxygen use, and measures to prevent hypothermia in very preterm infants have been updated in the light of the findings of randomised controlled trials.

Neonatal resuscitation is among the most important and commonly performed medical interventions world wide. The recent international collaboration in seeking and evaluating the evidence underpinning current practice has been a great and important advance. A major finding of this process is, however, a cause for serious concern: there is little evidence to evaluate. With the exceptions of suctioning for meconium, ${ }^{30}{ }^{31}$ polyethlyene wrapping to prevent hypothermia, ${ }^{32} 33$ and oxygen administration, ${ }^{34}$ trials of resuscitation interventions of sufficient power or scientific rigour have not been published (table 1). Only about 7000 infants have ever been recruited to trials evaluating any aspect of neonatal resuscitation, an intervention to which millions of infants are subjected annually. Recommendations therefore remain largely based on consensus. The challenge for neonatologists today is to produce robust evidence to support or refute these recommendations. In this era of evidence based medicine, it is chastening that a paragraph that first appeared as an introduction in 1953 remains so apt a conclusion today:

"Resuscitation of infants at birth has been the subject of many articles. Seldom have there been such imaginative ideas, such enthusiasms, and dislikes, and such unscientific observations and study about one clinical picture. There are outstanding exceptions to these statements, but the poor quality and lack of precise data of the majority of papers concerned with infant resuscitation are interesting."

Virginia Apgar ${ }^{22}$

\section{ACKNOWLEDGEMENTS}

Many thanks to Thomas F Baskett for assistance with the illustration.
Authors' affiliations

C P F O'Donnell, P G Davis, Royal Women's Hospital Melbourne and University of Melbourne, Victoria, Australia

A T Gibson, Sheffield Teaching Hospitals NHS Trust, Sheffield, UK

Competing interests: none declared

\section{REFERENCES}

1 The Bible (King James Version). II Kings. Chapter 4, verse 32-36.

2 Babylonian Talmud (translated by Michael L Rodkinson). Book I, Volume II, Chapter XVIII. Regulations regarding the clearing off of required space, the assistance to be given to cattle when giving birth to their young and to women about to be confined. Chapter XVIII, Page 282. 1903.

3 Henderson $Y$. The prevention and treatment of asphyxia in the newborn. JAMA 1928;90:583-6.

4 Milner AD. Resuscitation of the newborn. Arch Dis Child 1991:66:66-9.

5 Wiswell TE, Gibson AT. Historical evolution of neonatal resuscitation, American Academy of Pediatrics, Neonatal Resuscitation Program, Instructor Resources, 2005.

6 Raju TNK. History of neonatal resuscitation: tales of heroism and desperation. Clin Perinatol 1999:26:629-40.

7 Galanakis E. Apgar score and Soranus of Ephesus. Lancet 1998;352:2012-13.

8 Zaichkin J, Wiswell TE. The history of neonatal resuscitation. Neonatal Netw 2002;21:21-8.

9 Chameides L. Resuscitation: a historical overview, American Academy of Pediatrics, Neonatal Resuscitation Program Instructor Update (http:// www.aap.org/nrp/nrpmain.html) 7 (1 Feb), 1998.

10 Baskett TF. The resuscitation greats. Benjamin Pugh: the air-pipe and neonatal resuscitation, Resuscitation 2000:44:153-5.

11 Baskett TF, Nagele F. Bernhard Schultze and the swinging neonate. Resuscitation 2001;51:3-6.

12 Rennie JM, Roberton NRC. Textbook of neonatology. Edinburgh: Churchill Livingstone, 1999.

13 Flagg PJ. Treatment of asphyxia in the newborn. JAMA 1928;91:788-91.

14 Blaikely JB, Gibberd GF. Asphxia neonatorum: its treatment by tracheal intubation. Lancet 1935:736-9.

15 Akerren Y, Furstenberg N. Gastrointestinal administration of oxygen in treatment of asphyxia in the newborn. J Obstet Gynaecol Br Emp 1950;57:705-13.

16 James LS, Apgar VA, Burnard ED, Moya F. Intragastric oxygen and resuscitation of the newborn. Acta Paediatr 1963:52:245-51.

17 Bloxsom AP. Resuscitation of the newborn infant: use of the positive pressure oxygen-air lock. J Pediatr 1950;37:311-19.

18 Reichelderfer TE, Nitowsky HM. A controlled study on the use of the Bloxsom air lock. Pediatrics 1956;18:918-27.

19 Hutchison JH, Kerr MM, Inall JA, et al. Controlled trials of hyperbaric oxygen and tracheal intubation in asphyxia neonatorum. Lancet 1966;1:935-9.

20 Baskett P. Obituary: Peter J. Safar. Resuscitation 2003;59:3-5.

21 Baskett P, Zorab J, Lim A. Obituary: Henning Ruben. Resuscitation 2005:64:253-6.

22 Apgar V. A proposal for a new method of evaluation of the newborn infant. Anesth Analg, 1953;32, 260-7.

23 American Academy of Pediatrics Neonatal Resuscitation Program. International activities. American Academy of Pediatrics Neonatal Resuscitation Program, 2005.

24 In: Richmond S, ed. Resuscitation at birth: newborn life support provider manual. London: Resuscitation Council (UK), 2001

25 Kattwinkel J, Niermeyer S, Nadkarni V, et al. An Advisory Statement From the Pediatric Working Group of the International Liaison Committee on Resuscitation. Pediatrics 1999;103:e56.

26 Cummins RO, Chamberlain DA. Advisroy statements of the International Liaison Committee on Resuscitation. Circulation 1997;95:2172-3.

27 Nadkarni V, Hazinski MF, Zideman D, et al. Pediatric resuscitation: an advisory statement from the International Liaison Committee on Resuscitation. Circulation 1997:95:2185-95.

28 Contributors and Reviewers for the Neonatal Resuscitation Guidelines. International guidelines for neonatal resuscitation: an excerpt from the guidelines 2000 for cardiopulmonary resuscitation and emergency cardiovascular care: international consensus on science. Pediatrics 2000;106:e29.

29 International Liaison Committee on Resuscitation. Part 7: Neonatal Resuscitation. Resuscitation 2005;67:293-303.

30 Wiswell TE, Gannon CM, Jacob J, et al. Delivery room management of the apparently vigorous meconium-stained neonate: results of the multicenter, international collaborative trial. 2000;106: 867, Pediatrics 2000;105:1-7.

31 Vain NE, Szyld EG, Prudent LM, et al. Oropharyngeal and nasopharyngeal suctioning of meconium-stained neonates before delivery of their shoulders: multicentre, randomised controlled trial. Lancet 2004;364:560-1.

32 Vohra S, Frent G, Campbell V, et al. Effect of polyethylene occlusive skin wrapping on heat loss in very low birth weight infants at delivery: a randomized trial. J Pediatr 1999;134:547-51

33 Vohra S, Roberts RS, Zhang B, et al. Heat Loss Prevention (HeLP) in the delivery room: A randomized controlled trial of polyethylene occlusive skin wrapping in very preterm infants. J Pediatr 2004;145:750-3.

34 Saugstad OD, Ramji S, Vento M. Resuscitation of depressed newborn infants with ambient air or pure oxygen: a meta-analysis. Biol Neonate 2005;87:27-34. 
35 Drew JH. Immediate intubation at birth of the very-low-birth-weight infant. Effect on survival. Am J Dis Child 1982;136:207-10.

36 Davies VA, Rothberg AD, Argent AC, et al. A comparison of two resuscitators in the management of birth asphyxia. S Afr Med J 1985;68:19-22

37 Ramii S, Ahuja S, Thirupuram S, et al. Resuscitation of asphyxic newborn infants with room air or 100\% oxygen. Pediatr Res 1993:34:809-12.

38 Saugstad OD, Rootwelt T, Aalen O. Resuscitation of asphyxiated newborn infants with room air or oxygen: an international controlled trial: the Resair 2 study. Pediatrics 1998;102:el.

39 Vento M, Asensi M, Sastre J, et al. Resuscitation with room air instead of $100 \%$ oxygen prevents oxidative stress in moderately asphyxiated term neonates. Pediatrics 2001;107:642-7.

40 Ramii S, Rasaily R, Mishra PK, et al. Resuscitation of asphyxiated newborns with room air or $100 \%$ oxygen at birth: a multicentric clinical trial. Indian Pediatr 2003;40:510-17.

41 Vento $M$, Asensi M, Sastre J, et al. Oxidative stress in asphyxiated term infants resuscitated with 100\% oxygen. J Pediatr 2003;142:240-6.
42 Lokesh L, Kumar P, Murki S, et al. A randomized controlled trial of sodium bicarbonate in neonatal resuscitation-effect on immediate outcome. Resuscitation 2004;60:219-23.

43 Finer NN, Carlo WA Duara S, et al. Delivery room continuous positive airway pressure/positive end-expiratory pressure in extremely low birth weight infants: a feasibility trial. Pediatrics 2004;114:651-7.

44 Bajaj N, Udani RH, Nanavati RN. Room air vs. 100 per cent oxygen for neonatal resuscitation: a controlled clinical trial, J Trop Pediatr 2005:51:206-11.

45 Harling AE, Beresford MW, Vince GS, et al. Does the use of $50 \%$ oxygen at birth in preterm infants reduce lung injury? Arch Dis Child Fetal Neonatal Ed 2005;90:F401-5.

46 Harling AE, Beresford MW, Vince GS, et al. Does sustained lung inflation at resuscitation reduce lung injury in the preterm infant? Arch Dis Child Fetal Neonatal Ed 2005;90:F406-10.

47 Lindner W, Hogel J, Pohlandt F. Sustained pressure-controlled inflation or intermittent mandatory ventilation in preterm infants in the delivery room? A randomized, controlled trial on initial respiratory support via nasopharyngeal tube. Acta Paediatr 2005;94:303-9.

\section{IMAGES IN NEONATAL MEDICINE}

\section{Congenital medulloblastoma}

A 14 day old baby girl was referred to the neonatal intensive care unit with poor feeding, respiratory distress, drowsiness, vomiting, and hypoactivity of one day duration. She was born by caesarean section to a 21 year old mother, gravida 1, para 1 , after an uneventful pregnancy. The baby appeared normal at birth, and Apgar scores were 9 and 10 at one and five minutes respectively. On physical examination, the baby was lethargic, hypotonic, and macrocephalic, with no suck or Moro reflex. Her anterior fontanelle measured $4 \mathrm{~cm}$ and was bulging. Other systems were normal. Magnetic resonance imaging revealed a mass with heterogenic intensity in the posterior fossa (fig 1). In T2A series, the mass had hyperintense cystic components and fibrous septations. The patient was operated on the following day. The pathology was consistent with a medulloblastoma. On histochemical examination tumour cells were positive with synaptophisin and vimentin, focal positive with S 100

Neonatal brain tumours are rare, accounting for about $1 \%$ of all paediatric tumours. Among these, neonatal medulloblastoma is extremely rare. ${ }^{1-3}$ Medulloblastoma occurs only in the posterior fossa, although it has been grouped with histologically similar tumours arising elsewhere as a primitive neuroectodermal tumour.

B Ermis, C Aydemir, O Taspinar Department of Pediatrics, Division of Neonatology, Karaelmas University, Zonguldak, Turkey F Cagavi

Department of Neurosergery, Karaelmas University B Bahadır

Department of Pathology, Karaelmas University

H Ozdemir

Department of Radiology, Karaelmas University

Correspondence to: Dr Ermis, bahriermis@yahoo.com Competing interests: none declared

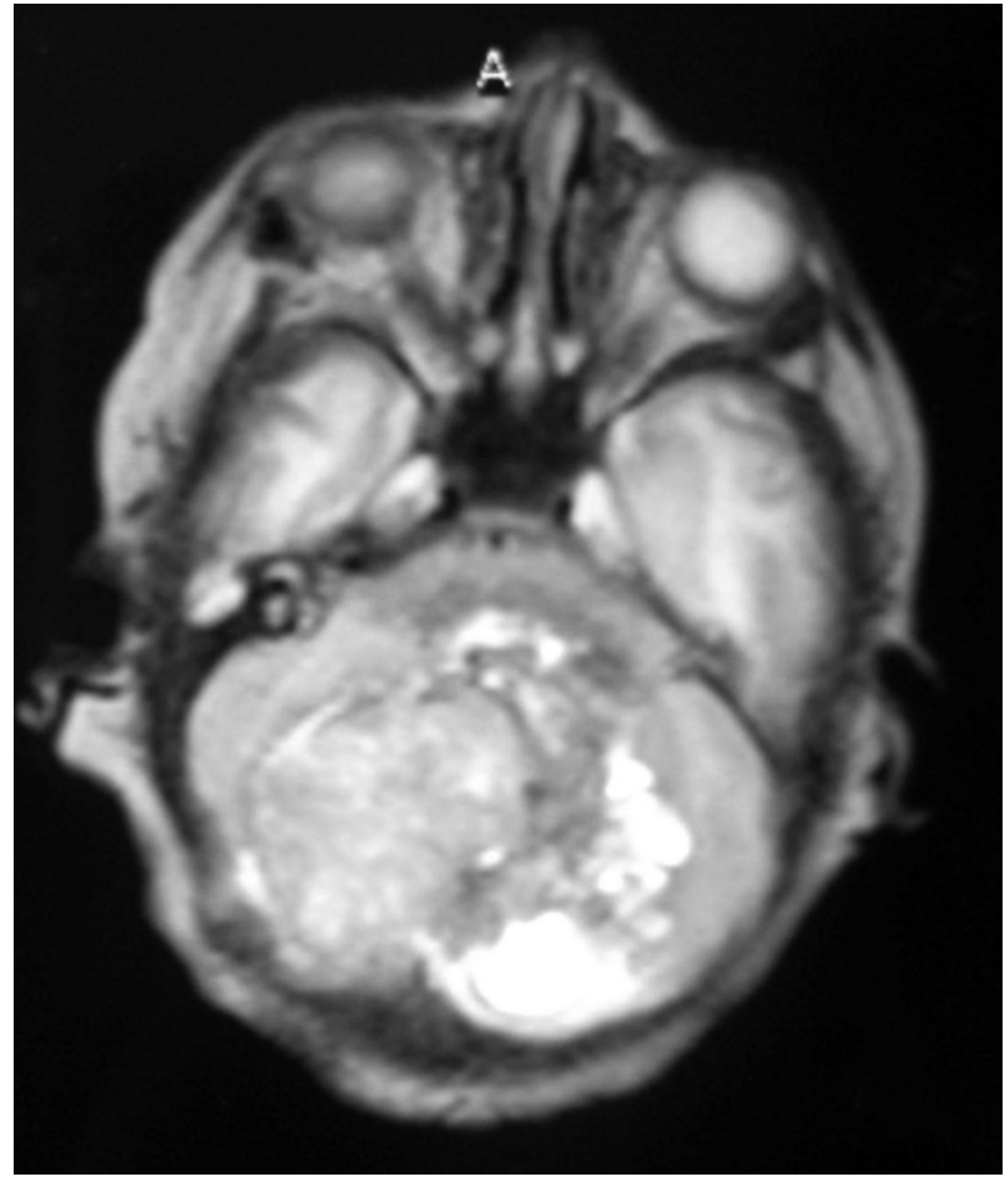

Figure 1 Magnetic resonance imaging scan showing a mass with heterogenic intensity in the posterior fossa. Permission for publication of this figure has been given by the patient's parents.

\section{REFERENCES}

1 Kim JH, Duncan C, Manuelidis EE. Congenital cerebellar medulloblastoma. Surg Neurol 1985;23:75-81

2 Kayama T, Yoshimoto T, Shimizu H, Sakurai Y. Neonatal medulloblastoma. J Neurooncol 1993;15:157-63.

3 Rocco CD, Ceddia A, lanelli A. Intracranial tumours in the first year of life. A report on 51 cases. Acta Neurochir 1993;123:14-24. 